\title{
SISTEM PENDUKUNG KEPUTUSAN PEREKOMENDASIAN OLI MENGGUNAKAN FUZZY MADM
}

\author{
Arief Kelik Nugroho ${ }^{1}$, Ipung Permadi ${ }^{2}$, Aini Hanifa $^{3}$ \\ 1,2,3 Jurusan Teknik Informatika, Universitas Jenderal Soedirman \\ Jawa Tengah, Indonesia
}

e-mail: ${ }^{1}$ arief.nugroho@unsoed.ac.id, ${ }^{2 i p u n g . p e r m a d i @ u n s o e d . a c . i d, ~}{ }^{3}$ ainihanifa@unsoed.ac.id

\begin{abstract}
Abstrak
Perekomendasian oli secara manual, tanpa menggunakan perhitungan yang akurat cenderung bersifat subyektif serta cukup sulit mengenali karakteristik oli yang paling tepat untuk jenis motor tertentu. Proses analisis data transaksi secara manual berdasarkan pada pengamatan akan mempengaruhi kualitas mesin. Sebagai contoh untuk memberikan rekomendasi oli terbaik bagi seorang konsumen, maka sebuah perusahaan/bengkel sepeda motor harus melihat data transaksi ganti oli yang lalu untuk mendapatkan data tentang oli yang digunakan untuk mengganti oli motor konsumen tersebut. Penggunaan perangkat komputer dapat digunakan sebagai pendukung keputusan menjadi lebih cepat, tepat, dan akurat. Proses perekomendasian oli terbaik bagi kendaraan bermotor menggunakan metode fuzzy dengan menginputkan parameterparameter ke sistem. Hasil perhitungan diperoleh direkomendasikan $\mathrm{A} 3=0.72, \mathrm{~A} 2=0.66$, $\mathrm{A} 1=0.55, \mathrm{~A} 4=0.40$.
\end{abstract}

Kata kunci: Fuzzy, Teknologi, Rekomendasi, oli, Sistem Pendukung Keputusan

\begin{abstract}
Manual oil recommendations, without the use of accurate calculations tend to be subjective and quite difficult to recognize the most appropriate oil characteristics for certain types of motorcycles. The process of analyzing transaction data manually based on observations will affect the quality of the machine. As an example to provide the best oil recommendations for a consumer, a motorcycle company / repair shop must look at the data of the last oil change transaction to get data about the oil used to change the customer's motor oil. The use of computer equipment can be used as a decision support to be faster, more precise, and accurate. The process of recommending the best oil for motor vehicles uses the fuzzy method by inputting parameters into the system. Calculation results obtained are recommended $A 3=0.72, A 2=0.66, A 1=0.55, A 4=0.40$.
\end{abstract}

Keywords : Fuzzy, Technology, Recommendations, Oil, Decision Support Systems

\section{PENDAHULUAN}

Peningkatan kebutuhan akan analisis data yang efisien dan efektif secara tidak langsung membuat suatu perusahaan beralih dari sistem manual ke sistem komputer. Penggunaan komputer akan mempermudah dan mempercepat proses analisis sehingga hasil analisis dapat langsung digunakan untuk mendukung perusahaan dalam menjalankan usahanya. Data yang dianalisis berupa data transaksi yang sudah tersimpan selama bertahun- tahun. Data tersebut sekilas tidak berharga, tetapi jika dikaji lebih mendalam sebenarnya tersimpan suatu pola tersembunyi dalam data transaksi tersebut yang sangat berharga bagi pemiliknya.

Perusahaan jasa perbengkelan memiliki permasalahan ketika dimintai rekomendasi jenis oli terbaik. Setiap jenis sepeda motor memiliki karakter mesin yang berbeda dan komponen penyusun mesin yang berbeda. Bengkel juga menjual oli sepeda motor berbagai merk dan masing- 
masing menawarkan kelebihannya. Bengkel mencatat secara manual ketika seorang pelanggan mengganti oli bagi sepeda motornya dan juga mencatat apa efek penggunaan oli tersebut. Data penggunaan oli dan efek penggunaannya tersebut dicatat.

Perekomendasian oli secara manual, tanpa menggunakan perhitungan yang akurat cenderung bersifat subyektif dan menguras pemikiran karena cukup sulit menghafal oli yang paling tepat untuk jenis motor tertentu. Jika hal ini tetap dilakukan dikhawatirkan motor pelanggan akan mendapatkan oli yang tidak sesuai, yang akhirnya akan merugikan pelanggan maupun perusahaan.

Penggunaan perangkat komputer digunakan dalam proses analisis menjadi lebih akurat dan lebih efisien. Selama ini, permasalahan yang dihadapi perusahaan antara lain proses analisis data transaksi secara manual,hanya berdasarkan pada pengamatan dan analisis ringan. Sebagai contoh untuk memberikan rekomendasi oli terbaik bagi seorang konsumen, maka sebuah perusahaan/bengkel motor harus melihat data transaksi ganti oli yang lalu untuk mendapatkan data tentang oli yang digunakan untuk mengganti oli motor konsumen tersebut.

Metode sistem pendukung keputusan yang dapat dipakai untuk mengambil keputusan dengn banyak alternatif pilihan dan dengan beberapa kriteria adalah Fuzzy MADM. Diharapkan metode ini tepat untuk diterapkan pada penentuan oli terbaik kendaraan bermotor dengan pendeatan statistik[5,6,8]

\section{TEORI}

\section{A. Fuzzy MADM (Multiple Attribute Decision Making).}

Fuzzy MADM (Multiple Attribute Decision Making), Penentuan alternatifalternatif yang ditetapakan berdasarkan prioritas pada awal sehingga pengambil keputusan harus menentukan prioritas atau ranking berdasarkan kriteria yang diberikan. Secara umum, Fuzzy MADM memiliki suatu tujuan tertentu, yang dapat diklasifikasikan dalam 2 tipe, yaitu (5)yaitu menyeleksi alternatif dengan atribut (kriteria) dengan ciri-ciri terbaik; dan mengklasifikasi alternatif berdasarkan peran tertentu. Untuk menyelesaikan masalah FMADM, dibutuhkan 2 tahap, yaitu $[5,6]$ :

a. Membuat rating pada setiap alternatif berdasarkan agregasi derajat kecocokan pada semua kriteria;

b. Merangking semua alternatif untuk mendapatkan alternatif terbaik. Ada 2 cara yang dapat digunakan dalam proses perankingan, yaitu melalui defuzzy atau melalui relasi preferensi fuzzy. Metode defuzzyfikasi dapat dilakukan dengan membuat bentuk dari bilangan fuzzy, proses perankingan berdasar atas bilangan crisp tersebut. Penggunaan relasi preferensi fuzzy lebih menjamin ketidakpastian yang melekat pada bilangan fuzzy hingga proses perankingan $[2,4,5]$.

\section{B. Fuzzy MADM}

Fuzzy MADM model Yager ini merupakan bentuk standar dari fuzzy MADM. Misalkan $A=\{a 1, \ldots$, an $\}$ adalah himpunan alternatif, dan atribut direpresentasikan dengan himpunan fuzzy $, j=1, \ldots, m$. Bobot yang menunjukkan tingkat kepentingan atribut ke-j dinotasikan dengan wj. Nilai capaian alternatif ai terhadap atribut diekspresikan dengan derajat keanggotaan $\mathrm{C}\left(\mathrm{x}_{\mathrm{i}}\right)$ [2]. Keputusan akhir diambil berdasarkan interseksi dari semua atribut fuzzy

Alternatif optimal didefinisikan sedemikian rupa sehingga alternatif tersebut memberikan konstribusi derajat keanggotaan.

Langkah-langkah penyelesaian untuk model ini adalah[6]:

a. Tetapkan matriks perbandingan berpasangan antar atribut, $\mathrm{M}$, berdasarkan prosedur hirarki sebagai berikut: 


$$
M=\left[\begin{array}{cccc}
\frac{\alpha_{1}}{\alpha_{1}} & \frac{\alpha_{1}}{\alpha_{2}} & \cdots & \frac{\alpha_{1}}{\alpha_{n}} \\
\frac{\alpha_{2}}{\alpha_{1}} & \cdots & & \frac{\alpha_{2}}{\alpha_{n}} \\
\vdots & & & \vdots \\
\frac{\alpha_{n}}{\alpha_{1}} & \frac{\alpha_{n}}{\alpha_{2}} & \cdots & \frac{\alpha_{n}}{\alpha_{n}}
\end{array}\right]
$$

dengan adalah kepentingan relatif atribut ai terhadap atribut aj. yang nilainya ada pada kisaran 1 sampai 9 seperti yang terdapat dalam Tabel 1.

Tabel 1. Keterangan Skala

\begin{tabular}{ll}
\hline Skala & Kepentingan relatif antara atribut $a_{i}$ terhadap $a_{i}$ \\
\hline 1 & Sama-sama penting \\
3 & Sedikit lebih penting \\
5 & Lebih penting \\
7 & Sangat lebih penting \\
9 & Sangat-jauh lebih penting \\
$2,4,6,8$ & Nilai antara dari skala diatas
\end{tabular}

b. Tentukan bobot $w_{j}$

c. Hitung nilai:

$$
\left(\tilde{C}_{j}\left(x_{i}\right)\right)^{w} j
$$

d. Tentukan irisan dengan menggunakan fungsi $\min \left(\tilde{C}_{j}\left(x_{i}\right)\right)^{w_{j}}$, sebagai:

$\tilde{D}=\left\{\left(x_{i}, \min _{j}\left(\mu_{C j}\left(x_{i}\right)\right)^{w} j\right) i=1, \ldots, n ; j=1, \ldots, m\right\}(3)$

e. Pilih $x_{i}$ dengan derajat keanggotaan terbesar dalam, dan tetapkan sebagai alternatif optimal.

\section{Sistem Pendukung Keputusan}

Sistem Pendukung Keputusan adalah sebagai suatu sistem yang dimaksudkan untuk mendukung para pengambil keputusan manajerial pada permasalahan semi terstruktur(1)(7).

\section{METODE}

\section{A. Proses Perekomendasian}

Proses yang dilakukan untuk menghasilkan rekomendasi adalah data cleaning, proses transformasi data dan proses clustering data. Dari hasil proses clustering data untuk diproses lanjut dengan fuzzy MADM model Yager dengan menghitung matriks . Dari hasil perhitungan matriks menghasilkan perekomendasian oli

terbaik. Secara garis besar proses perekomendasian oli disajikan pada gambar 1.

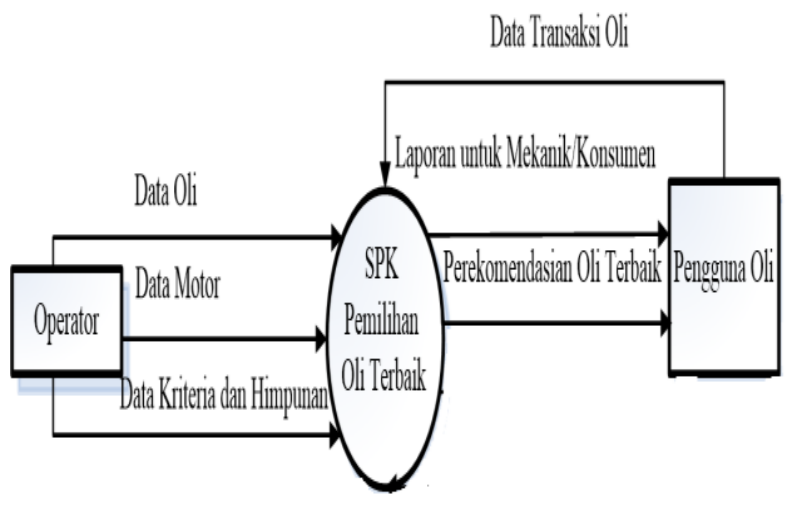

Gambar 1. Proses kerja sistem

Gambar 1 menjelaskan bahwa pengguna oli menginputkan data transaksi oli dan manager menjalankan proses perhitungan matriks. Output yang dihasilkan dari proses rekomendasi pemilihan Oli berupa perhitungan matriks yang direkomendasikan berdasarkan memilih bobot paling kecil dari keseluruhan kriteria pada tiap oli yang diberikan oleh sistem pendukung keputusan pemilihan oli terbaik. Setelah input data diproses dalam sistem pendukung keputusan pemilihan oli terbaik dan operator dapat membuat laporan perekomendasian oli terbaik yang ditujukan 
pada pimpinan dan mekanik atau konsumen.

HASIL DAN PEMBAHASAN

\section{A. Perancangan Proses}

Perancangan proses dengan menggunakan data yang terdiri data oli, data motor, data kriteria dan himpunan sesuai gambar 2. Program akan melakukan proses sesuai dengan kriteria yang dimasukkan beserta derajat keanggotaan setiap alternatif pada setiap atribut sehingga nanti akan menghasilkan oli terbaik bagi tipe sepeda motor, dimana oli terbaik merupakan alternatif pilihan yang diberikan oleh sistem untuk proses rekomendasi.

Pada penelitian ini perusahaan dibidang jasa perbengkelan merekomendasikan oli terbaik sepeda motor dalam 17 pilihan jenis oli.

\section{B. Data Kriteria dan Bobot Himpunan}

Bobot Himpunan memiliki 4 buah atribut seperti yang ditunjukkan pada tabel 1 , tabel 2, tabel 3 dan tabel 4 yaitu Volume Oli, Karbon Dalam Oli, Gangguan mesin, Kerusakan Mesin. Fungsi tabel ini untuk menyimpan bobot himpunan berdasarkan variabel fuzzy.

Volume oli, dengan bobot himpunan seperti tabel 2. Karbon dalam oli, dengan bobot himpunan seperti pada tabel 3

Gambar 2. Diagram Perekomendasian

Tabel 2 . Himpunan Volume Oli

\begin{tabular}{ll}
\hline Himpunan & Keterangan \\
\hline Sangat Banyak & $\begin{array}{l}\text { Jika jumlah oli yang dikeluarkan dari mesin (diganti) sama volumenya } \\
\text { dengan saat dimasukkan }\end{array}$ \\
Banyak & Jika jumlah oli kotor berkurang hingga 1/10 dari oli saat dimasukkan \\
Sedang & Jika jumlah oli kotor berkurang hingga 3/10 dari oli saat dimasukkan \\
Sedikit & Jika jumlah oli kotor berkurang hingga 5/10 dari oli saat dimasukkan \\
Tidak Ada & Jika jumlah oli kotor berkurang hingga 7/10 dari oli saat dimasukkan \\
\hline
\end{tabular}

Tabel 3. Himpunan Karbon Dalam Oli

Himpunan Keterangan

\begin{tabular}{ll}
\hline Tidak Ada & $\begin{array}{l}\text { Jika tingkat kebeningan oli yang dikeluarkan dari mesin (diganti) } \\
\text { sama dengan saat dimasukkan }\end{array}$ \\
Sedikit & Jika oli yang dikeluarkan dari mesin (diganti) berwarna lebih \\
& gelap 1 tingkat daripada saat dimasukkan
\end{tabular}


Sedang

Jika oli yang dikeluarkan dari mesin (diganti) berwarna lebih gelap 2 tingkat daripada saat dimasukkan

Banyak Jika oli yang dikeluarkan dari mesin (diganti) berwarna lebih gelap 3 tingkat daripada saat dimasukkan

Sangat Banyak Jika oli yang dikeluarkan dari mesin (diganti) berwarna lebih gelap 4 tingkat daripada saat dimasukkan

dengan bobot himpunan pada tabel 4 .

Tabel 4. bobot Gangguan mesin

\begin{tabular}{|c|c|}
\hline Himpunan & Keterangan \\
\hline Tidak Ada & Jika motor tidak terjadi gangguan kinerja sama sekali akibat oli \\
\hline Sedikit & $\begin{array}{l}\text { Jika motor terjadi gangguan kinerja maksimal } 5 \text { kali akibat oli, atau } \\
\text { gangguan ringan seperti cepat panas atau "ngebul" lebih banyak } \\
\text { daripada biasanya }\end{array}$ \\
\hline Sedang & $\begin{array}{l}\text { Jika motor terjadi gangguan kinerja maksimal } 10 \text { kali akibat oli, } \\
\text { atau gangguan sedang seperti mati mesin mendadak }\end{array}$ \\
\hline Banyak & $\begin{array}{l}\text { Jika motor terjadi gangguan kinerja maksimal } 15 \text { kali akibat oli, } \\
\text { atau gangguan berat seperti mesin macet tidak mau hidup kecuali } \\
\text { dipaksa }\end{array}$ \\
\hline Sangat Banyak & $\begin{array}{l}\text { Jika motor terjadi gangguan kinerja maksimal } 20 \text { kali akibat oli, } \\
\text { atau gangguan sedang seperti mesin macet tidak mau hidup sama } \\
\text { sekali }\end{array}$ \\
\hline
\end{tabular}

Kerusakan Mesin akibat penggunaan oli, dengan bobot himpunan seperti pada tabel

4.

Tabel 5. Bobot kerusakan mesin

\begin{tabular}{ll}
\hline Himpunan & Keterangan \\
\hline Tidak Ada & $\begin{array}{l}\text { Jika motor tidak terjadi kerusakan sama sekali akibat oli } \\
\text { Jika motor terjadi kerusakan ringan komponen sekunder } \\
\text { akibat oli }\end{array}$ \\
Sedang & $\begin{array}{l}\text { Jika motor terjadi kerusakan sedang komponen sekunder } \\
\text { dan rusak ringan komponen primer akibat oli }\end{array}$ \\
Banyak & $\begin{array}{l}\text { Jika motor terjadi kerusakan minimal sedang komponen } \\
\text { sekunder dan rusak sedang komponen primer akibat oli }\end{array}$ \\
Sangat Banyak & $\begin{array}{l}\text { Jika motor terjadi kerusakan minimal sedang komponen } \\
\text { sekunder dan rusak minimal sedang komponen primer } \\
\text { akibat oli }\end{array}$
\end{tabular}




\section{Data Cleaning}

Pemilihan alternatif tersebut didasarkan atas 4 kriteria, yaitu: $C^{1}=$ volume, $C^{2}=$ Jumlah Karbon, $\mathrm{C}^{3}=$ Gangguan Mesin,$C^{4}=$ Kerusakan Mesin. Data cleaning berfungsi untuk menyeleksi data yang akan diproses lebih lanjut dalam pemrosesan data. Data yang digunakan data transaksi bagi kendaraan dengan nomor polisi dan jenis motor yang sama, hasil data cleaning di

Tabel 6. Tabel konversi himpunan fuzzy ke Bobot

\begin{tabular}{lll}
\hline Kriteria & Himpunan & Bobot \\
\hline Volume & Banyak & 0,8 \\
& Sangat Banyak & 0,9 \\
& Sedang & 0,6 \\
& Sedikit & 0,4 \\
Karbon & Tidak Ada & 0,1 \\
& Banyak & 0,8 \\
& Sangat Banyak & 0,9 \\
& Sedang & 0,6 \\
Gangguan Mesin akibat penggunaan & Sedikit & 0,4 \\
Akibat Oli & Tidak Ada & 0,3 \\
& Sidak Ada & 1 \\
& Sedikit & 0,8 \\
Kerusakan Mesin & Sedang & 0,6 \\
Akibat penggunaan Oli & Banyak & 0,4 \\
& Sangat Banyak & 0,2 \\
& Tidak Ada & 1 \\
& Sedikit & 0,8 \\
& Sedang & 0,6 \\
& Banyak & 0,4 \\
& Sangat Banyak & 0,2 \\
\hline
\end{tabular}

\section{E. Proses Data Clustering}

Tabel 8. Tabel Keterangan Matriks

Kriteria

Atribut

Volume Jumlah Karbon Gangguan Mesin Kerusakan Mesin

Jenis Oli

\begin{tabular}{lrrrl} 
CASTROL-SM & .76 & .71 & .72 & .76 \\
FEDERAL-SM & .83 & .81 & .91 & .87 \\
MOTUL-SM & .83 & .82 & .99 & 1 \\
TOP1-SM & .66 & .66 & .68 & .74 \\
\hline
\end{tabular}


Tabel 9. Tabel Matriks

\begin{tabular}{lllll}
\hline & $\mathrm{C}_{1}$ & $\mathrm{C}_{2}$ & $\mathrm{C}_{3}$ & $\mathrm{C}_{4}$ \\
\hline $\mathrm{C}_{1}$ & 1 & 3 & 5 & 7 \\
$\mathrm{C}_{2}$ & $1: 3$ & 1 & 4 & 5 \\
$\mathrm{C}_{3}$ & $1: 5$ & $1: 4$ & 1 & 4 \\
$\mathrm{C}_{4}$ & $1: 7$ & $1: 5$ & $1: 4$ & 1 \\
\hline
\end{tabular}

Tabel 10. Tabel Keterangan Matriks

\begin{tabular}{|c|c|}
\hline $\begin{array}{l}\text { Perbandingan } \\
\text { Kriteria }\end{array}$ & Penjelasan \\
\hline $\mathrm{C}^{1}$ dengan $\mathrm{C}^{2}$ & $\begin{array}{l}\text { Kriteria C1 untuk dipakai sebagai parameter dalam menentukan oli terbaik } \\
\text { daripada C2 dengan nilai perbandingan adalah } 1 / 3 \text {. }\end{array}$ \\
\hline $\mathrm{C}^{1}$ dengan $\mathrm{C}^{3}$ & $\begin{array}{l}\text { Kriteria } C 1 \text { untuk dipakai sebagai parameter dalam menentukan oli terbaik } \\
\text { daripada } C 3 \text { dengan nilai perbandingan antara } C 3 \text { dengan } C 1 \text { adalah } 1 / 5 \text {. }\end{array}$ \\
\hline $\mathrm{C}^{2}$ dengan $\mathrm{C}^{3}$ & $\begin{array}{l}\text { Kriteria C2 untuk dipakai sebagai parameter dalam menentukan oli terbaik } \\
\text { daripada C3 dengan nilai perbandingan antara C3 dengan } C 2 \text { adalah } 1 / 4 \text {. }\end{array}$ \\
\hline$C^{1}$ dengan $C^{4}$ & $\begin{array}{l}\text { Kriteria } C 1 \text { untuk dipakai sebagai parameter dalam menentukan oli terbaik } \\
\text { daripada } C 4 \text { dengan nilai perbandingan } C 4 \text { dengan } C 1 \text { adalah } 1 / 7\end{array}$ \\
\hline$C^{2}$ dengan $C^{4}$ & $\begin{array}{l}\text { Kriteria C2 untuk dipakai sebagai parameter dalam menentukan oli terbaik } \\
\text { daripada C4 nilai perbandingan C4 dengan C2 adalah } 1 / 5 \text {. }\end{array}$ \\
\hline $\mathrm{C}^{3}$ dengan $\mathrm{C}^{4}$ & $\begin{array}{l}\text { Kriteria C3 untuk dipakai sebagai parameter dalam menentukan oli terbaik } \\
\text { daripada C4. Nilai perbandingan antara C4 dengan C3 adalah } 1 / 4 \text {. }\end{array}$ \\
\hline
\end{tabular}

Dari matrik pada tabel 9 dihitung untuk mendapatkan nilai bobot (Weight) seperti pada Tabel 11. Jumlahkan elemen-elemen pada setiap kolom:

Tabel 11. Tabel Hasil Komputasi Matriks

\begin{tabular}{lllll}
\hline & $\mathrm{C}^{1}$ & $\mathrm{C}^{2}$ & $\mathrm{C}^{3}$ & $\mathrm{C}^{4}$ \\
\hline $\mathrm{C}^{1}$ & 1 & 3 & 5 & 7 \\
$\mathrm{C}^{2}$ & 0.3 & 1 & 4 & 5 \\
$\mathrm{C}^{3}$ & 0.2 & 0.3 & 1 & 4 \\
$\mathrm{C}^{4}$ & 0.14 & 0.2 & 0.3 & 1 \\
\hline
\end{tabular}

Tabel 12. Tabel Hasil Bagi

\begin{tabular}{lllll}
\hline & $C^{1}$ & $C^{2}$ & $C^{3}$ & $C^{4}$ \\
\hline$C^{1}$ & 0.59 & 0.67 & 0.48 & 0.41 \\
$C^{2}$ & 0.19 & 0.22 & 0.39 & 0.29 \\
$C^{3}$ & 0.11 & 0.05 & 0.09 & 0.23 \\
$C^{4}$ & 0.08 & 0.04 & 0.02 & 0.05 \\
\hline
\end{tabular}

Dari tabel 6 di atas maka hasil perhitungan diperoleh bobot nilai sebagai berikut : $2.15 ; 1.09 ; 0.48 ; 0.19$

Bobot nilai dijadikan pemangkat pada data rekap penggunaan oli sehingga diperoleh tabel hasil pemangkatan tabel 10 kemudian dapat dihitung $\left(\mathrm{C}_{\mathrm{j}}\left(\mathrm{X}_{\mathrm{i}}\right)^{\mathrm{wj}}\right.$ sebagai berikut :

$\mathrm{C}_{1}\left(\mathrm{x}_{1,2,3,4}\right)^{2.15}=$ $\left\{\left(x_{1}=0.55\right)\left(x_{2}=0.66\right)\left(x_{3}=0.72\right)\left(x_{4}=0.40\right)\right\}$

$\mathrm{C}_{2}\left(\mathrm{x}_{1,2,3,4}\right)^{1.09}=$ $\left\{\left(x_{1}=0.68\right)\left(x_{2}=0.79\right)\left(x_{3}=0.8\right)\left(x_{4}=0.63\right)\right\}$

$\mathrm{C}_{3}\left(\mathrm{x}_{1,2,3,4}\right)^{0.48}=$ $\left\{\left(x_{1}=0.85\right)\left(x_{2}=0.95\right)\left(x_{3}=0.99\right)\left(x_{4}=0.83\right)\right\}$

$\mathrm{C}_{4}\left(\mathrm{x}_{1,2,3,4}\right)^{0.19}=$ $\left\{\left(x_{1}=0.94\right)\left(x_{2}=0.97\right)\left(x_{3}=1\right)\left(x_{4}=0.94\right)\right\}$

Hasil perhitungan dapat di lihat pada tabel 13 
Tabel 13 Tabel Hasil

\begin{tabular}{lllll}
\hline Atribut & Kriteria & & & \\
\cline { 2 - 5 } Jenis Oli & Volume & Karbon dalam Oli & $\begin{array}{c}\text { Gangguan Mesin } \\
\text { Akibat Penggunaan Oli }\end{array}$ & $\begin{array}{c}\text { Kerusakan } \\
\text { Mesin }\end{array}$ \\
\hline 1 & 0.55 & 0.68 & 0.85 & 0.94 \\
2 & 0.66 & 0.79 & 0.95 & 0.97 \\
3 & 0.72 & 0.8 & 0.99 & 1 \\
4 & 0.40 & 0.63 & 0.83 & 0.94
\end{tabular}

Dengan menggunakan fungsi Min maka diperoleh : $\operatorname{Min}(0.55 ; 0.68 ; 0.85 ; 0.94)=$ $0.55 ; \quad \operatorname{Min}(0.55 ; 0.68 ; 0.85 ; 0.94)=0.55$; $\operatorname{Min}(0.72 ; \quad 0.80 ; \quad 0.99 ; 1.00)=0.72 ;$ $\operatorname{Min}(0.40 ; 0.63 ; 0.83 ; 0.94)=0.40 ;$ Dari hasil perolehan kemudian dicari nilai Maks $(0.72 ; 0.66 ; 0.55 ; 0.40)$ adalah 0.72 . Hasil rekomendasi diperoleh alternatif $A_{3}$ adalah alternatif yang terbaik yang akan dipilih. Dari hasil diatas diperoleh urutan rekomendasi oli dengan cara memilih bobot paling kecil dari keseluruhan kriteria pada tiap oli. Diperoleh bobot minimum dari oli jenis 1 adalah 0.55 , oli jenis 2 adalah 0.66 , oli jenis 3 adalah 0.72 , oli jenis 4 adalah 0 . 40. Maka diperoleh hasil oli yang direkomendasikan pada tabel 14

\begin{tabular}{lll}
\multicolumn{3}{c}{ Tabel 14. Rekomendasi Oli } \\
\hline Rangking & $\begin{array}{l}\text { Hasil } \\
\text { rekomendasi }\end{array}$ & Bobot \\
\hline 1 & A3 & 0.72 \\
2 & A2 & 0.66 \\
3 & A1 & 0.55 \\
4 & A4 & 0.40 \\
\hline
\end{tabular}

Dari hasil perhitungan dapat di simpulkan bahwa rekomendasi oli yang digunakan dengan kode $\mathrm{A} 3$ dengan bobot $72 \%$.

\section{A. Implementasi Sistem}

Kriteria dan himpunan berisi masukkan data antara lain kode kriteria dan kriteria. Halaman kriteria dan himpunan digunakan untuk melihat kriteria dan bobot himpunan yang digunakan untuk melakukan proses perekomendasian oli gambar 3

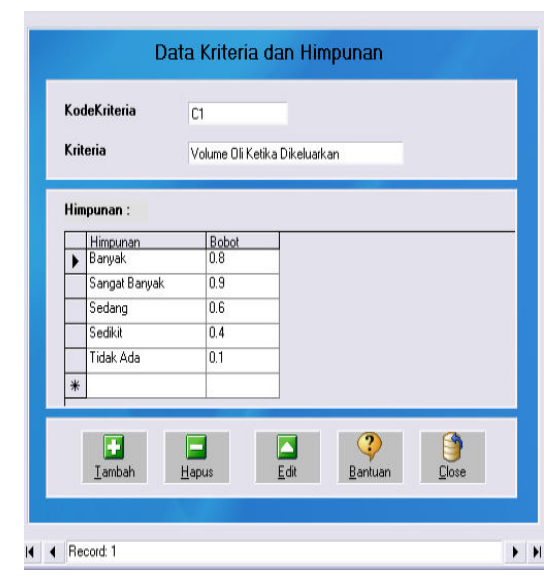

Gambar 3. Menu menset parameter nilai bobot

Proses data cleaning yang tidak relevan dengan data yang diperlukan pada proses analisis. Pada proses ini, akan dilakukan penghapusan data transaksi pada gambar 1 ganti oli bila memiliki jenis motor yang berbeda dengan jenis motor yang akan dilakukan proses analisis.

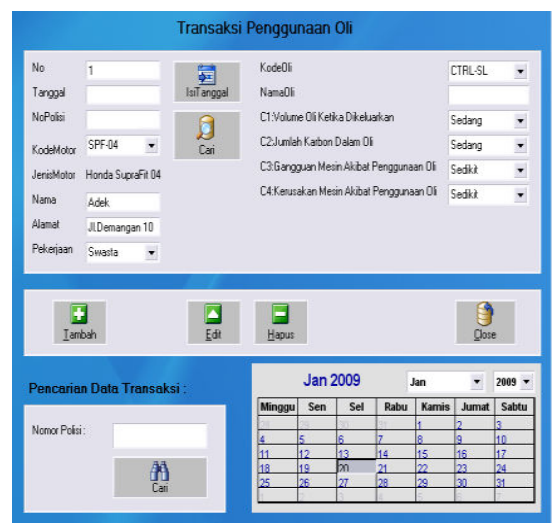

Gambar 4. Data transaksi Oli 
Gambar 4 adalah kelanjutan dari proses pertama. Menu dirancang untuk melakukan proses transformasi data ke bentuk numeris dengan proses pembobotan. Sehingga dapat menghasilkan data yang berbentuk numeris, agar nantinya dapat dihitung bobot masing-masing oli yang akan direkomendasikan pada proses clustering dari hasil transformasi data pada proses sebelumnya. Data penggunaan oli setiap alternatif oli dikumpulkan dan dibagi per kriteria untuk diproses lebih lanjut. untuk melanjutkan ke tahap empat yaitu penentuan matriks (gambar 5)

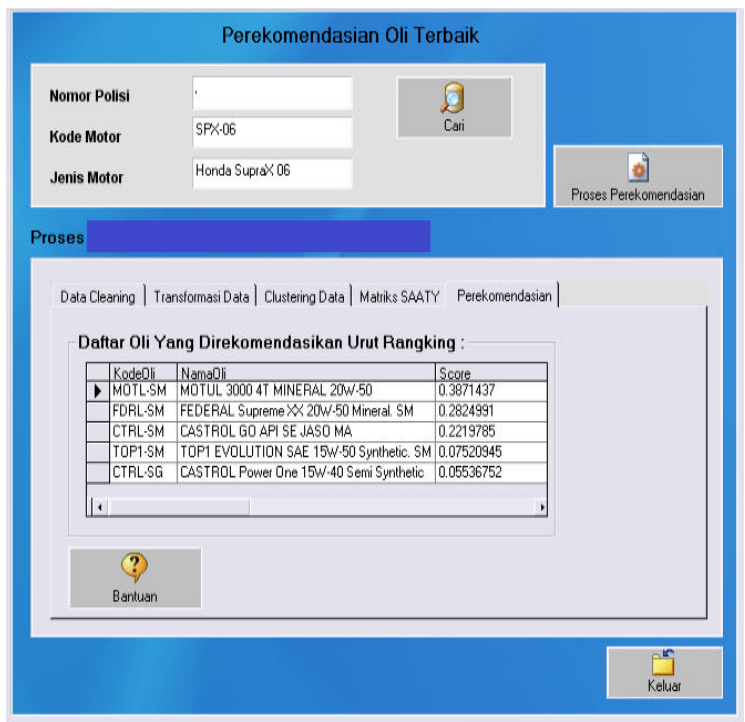

Gambar 5. Hasil rekomendasi berdasalkan kriteria

Halaman menu dirancang untuk menampilkan hasil proses rekomendasi oli. Proses ini merupakan bagian utama dari aplikasi ini, yaitu dihitungnya data penggunaan oli berikut kejadian ketika penggunaan oli dengan mengolah data yang telah diperoleh. Data dihitung sesuai dengan tahapan-tahaan sehingga memberikan hasil berupa perangkingan Oli manakah yang terbaik untuk motor tersebut.

\section{Kesimpulan}

$\begin{array}{crrr}\text { Penerapan Fuzzy } & \text { MADM untuk } \\ \text { Perekomendasian Oli } & \text { Terbaik } & \text { Bagi }\end{array}$ Kendaraan Bermotor yang digunakan untuk memberikan rekomendasi oli terbaik kepada pengguna dalam hal ini konsumen untuk memilih oli terbaik sesuai sepeda motornya. Metode Fuzzy dapat digunakan untuk medukung pengambilan keputusan dalam hal ini adalah keputusan dalam menentukan oli terbaik. Dari hasil perhitungan diperoleh $\operatorname{MESRAN}(\mathrm{A} 3)=0.72$, Enduro $(\mathrm{A} 2)=0.66$, Prima XP $(A 1)=0.55$, STP $(A 4)=0.40$. Bobot perangkingan yang diperoleh dari hasil penentuan pihak bengkel sangat mempengaruhi hasil rekomendasi

\section{REFERENSI}

[1] Kusrini. Konsep dan Aplikasi Sistem Pendukung Keputusan. Andi : Yogyakarta.2007.

[2] Kusumadewi S, Hartati S,Harjoko A and Retantyo W.Fuzzy Multi-Attribute Decision Making(MADM). Graha IImu: Yogyakarta.2006

[3] Macleod, R. J. Sistem Informasi Manajemen. Indeks : Jakarta.2004

[4] SM Liang, IC Wu, ZY Zhuang."Analitic Hierarchy Process a Tool to Explore the Success Factors of BIM Deployment in Construction Firm". in Proceedings of ISARC Conference,pp 897-905.2019.

[5] ZY Zhuang, CR Su, and SE Chang."The effectiveness of IF-MADM(intuitonisticfuzzy multi attribute decison making) for group decision:methode and empirical asseement for the selection of a senior centre"Technological and economic Development of Economy. Vol 25, pp 322-364.2019

[6] Zimmermann. Fuzzy set Theory and Its Application.Massachusetts:Kluwer Academic Publiser.1991

[7] Turban E, Aronson and Liang TP.Decision Support System and Intelligent System. Pearson.2005.

[8] Nugroho AK., Permadi I., Nofiyati , Ulfa SH.Sistem Pendukung Keputusan Penilaian Kesehatan Tanah Dengan Metode Simple Additive Weighting.Jurnal Pengembangan IT(JPIT).2019.Vol.04.No.01. Hal 61-69. 
[9] Nugroho AK, Iskandar D. "Algoritma Iterative Dichotomizer 3 (ID3) Pengambilan Keputusan".2015. Jurnal Dinamika Rekayasa. Vol.11.No.2

[10] Dwijayadi INAA, Pengembangan Sistem Pendukung Keputusan Penentuan Hotel Di Kecamatan Buleleng Dengan Metode Analytic Hierarchy Process (Ahp) Dan Technique For Others Reference By Similarity To Ideal Solution (Topsis).JANAPATI.2018.Vol. 7. No. 2. Hal.163-176 